\title{
Los mandatos de masculinidad en la cotidianeidad de la prisión
}

Masculinity mandates in daily life in prison

Malvina Marengo

Licenciada en Psicología

(Universidad Nacional de Córdoba)

Maestranda en Psicopatología y Salud

Mental

(Universidad Nacional de Rosario)

Correo: psi.malvinamarengo@gmail.com 


\section{Resumen}

En este escrito, se toman aportes de los estudios de género y del psicoanálisis para analizar los efectos que tiene la institución penitenciaria como productora y reproductora de mandatos patriarcales, a partir del relato teórico y vivencial de algunos aspectos de la cotidianeidad de la vida en la prisión. Para ello, será fundamental contemplar cómo se construyen las masculinidades de quiénes habitan esos espacios (detenidos y agentes penitenciarios) y qué roles desempeñan los otros hombres y las mujeres, entendiendo que tanto la violencia como el ejercicio de poder se constituyen en elementos ineludibles para un análisis institucional. Finalmente, se abre el siguiente interrogante: si no se cuestionan las estructuras patriarcales, ¿es este un lugar eficaz para enfrentar y tratar la violencia machista?

Palabras clave

Masculinidades, Violencia de género, Políticas penitenciarias, Ejercicio de poder.

\section{Abstract}

This article employs contributions from gender studies and psychoanalysis to analyse the effects of the penitentiary institution as a producer and reproducer of patriarchal mandates, based on the theoretical and experiential account of some aspects of daily life in prison. For this, it is essential to contemplate how the masculinities of those who inhabit these spaces (i.e. prisoners and penitentiary agents) are built, which roles other men and women play, understanding that both violence and the exercise of power constitute unavoidable elements for an institutional analysis. Finally the question arises: if the patriarchal structures are not questioned, is the prison an effective place to confront and deal with sexist violence?

Keywords

Masculinities, Gender violence, Penitentiary policies, Exercise of power. 


\section{Introducción}

En la actual coyuntura atravesada por los debates de género y la puesta en cuestión de las lógicas de poder enraizadas en los orígenes mismos del patriarcado, urge realizar una revisión de las instituciones que permean la vida en sociedad. A rasgos generales, podemos pensar que las instituciones surgen a partir de la necesidad de satisfacer una necesidad social, creando a partir de ello un sistema de normas, roles e ideologías que regulan su funcionamiento.

En sus inicios, la prisión tuvo la función de apartar al delincuente de la sociedad, otorgándole posteriormente una racionalidad científica, lo que da lugar a la serie de ideologías RE (reeducación, resocialización, reintegración) que en nuestro país se encuentran plasmadas en la Ley de Ejecución Penal No 24660.

Aun así, y tal como lo plantean algunos criminólogos como Máximo Sozzo (2008), en algún momento la prisión abandona la finalidad declarada de la corrección del criminal, abrazando otros objetivos como legitimación de su propia existencia, dando pie para la instauración de la llamada cárcel-depósito.

Pero aún en su función de depósito de los llamados por Wacquant (2004) desechos sociales, la cárcel es un territorio vivo, en donde lejos de la quietud a la que alude la idea de depósito, suceden cosas: se establecen vínculos de amistad, de amor, de competencia, de rivalidad, de autoridad, de comercio, y también transacciones que sostienen una lógica institucional y reproducen, a veces de forma magnificada, lo que sucede en la sociedad en su conjunto.

A partir del análisis de estos intercambios, podemos ver que la cárcel no escapa a los mandatos patriarcales, permeando y moldeando subjetividades. En este sentido, interesa analizar cómo esas estructuras de género se van colando en la cotidianeidad de la vida en la prisión, afectando a todes les que la habitan.

\section{Hablemos de patriarcado (y de sistema carcelario)}

Echando mano de los estudios de género, podemos pensar a la cárcel como una de las instituciones en donde la lógica patriarcal se cuela haciéndose evidente. Un sistema patriarcal se funda a partir de la dife- 
rencia anatómica entre hombres y mujeres, y de la asignación de roles distintos que ubican a estas últimas en una posición de inferioridad. Así, a lo largo del tiempo, las mujeres fueron relegadas al ámbito doméstico quedando a cargo de las tareas de cuidados y reproducción; por su parte, los hombres poblaron el espacio público, tomando las riendas de la productividad y el gobierno. Pero las ideologías patriarcales no sólo afectan a las mujeres al ubicarlas en un plano de inferioridad en la mayoría de los ámbitos de la vida, sino que restringen y limitan también a los hombres, a pesar de su estatus de privilegio, puesto que preservar su posición dominante y su sentido de la masculinidad, requiere de una revalidación constante.

El sistema patriarcal ha sido extraordinariamente flexible y ha variado en sus formas según la época y los lugares. No obstante, estos cambios dentro de la familia no alteran el predominio masculino sobre la esfera pública, las instituciones y el gobierno.

Laura Peretti menciona que "la cárcel es ese espacio conformado por redes y dispositivos de poder arbitrario comandado por hombres, en donde predominan las lógicas de vigilancia y corrección" (2018:105). Podríamos agregar que estos elementos se retroalimentan a sí mismos al funcionar de forma prácticamente autónoma, con escasos cuestionamientos a su estructura.

Quienes dirigen la institución son un puñado de varones con cargos jerárquicos que hacen uso del poder conferido para mantener el statu quo. Nada puede ser cuestionado ni modificado, y todo aquello que amenace el control sostenido debe ser puesto bajo vigilancia, cuando no eliminado. Así, esta triada de poder, control y vigilancia con la que Foucault describió en 1976 las funciones de la prisión también es la que describe las funciones masculinas dentro de un sistema patriarcal (Foucault, 1976).

Sin ahondar demasiado en los estudios sobre esto, podemos adherir a lo mencionado por Fernández Boccardo respecto de que "hay un acuerdo entre distintos autores en que la ideología patriarcal se sustenta en un modelo de hombre poderoso, superior, protector, viril, autosuficiente, y todos esos atributos se tienen que demostrar permanentemente" (2018:40). Por su parte, con respecto del mandato de masculinidad, Rita Segato dice que éste "exige al hombre probar- 
se hombre todo el tiempo; porque la masculinidad, a diferencia de la femineidad, es un estatus, una jerarquía de prestigio, se adquiere como un título y se debe renovar y comprobar su vigencia como tal" (2018:40).

En un espacio habitado mayoritariamente por hombres, resulta fundamental analizar esas relaciones que se tejen. Como bien lo describió Foucault (1976), la prisión es ese dispositivo que hace posible el interjuego de estrategias de poder, que permean todas las relaciones y los intercambios.

Usualmente, cuando se habla con perspectiva de género respecto de la cárcel es para referirnos a las mujeres detenidas y a cuánto de su situación puede ser explicada por la desigualdad histórica respecto de los hombres. Pero, en general, no suele hablarse de cómo las lógicas patriarcales inciden sobre la cotidianeidad de los varones detenidos ni de les trabajadores de las instituciones penitenciarias. Intentaremos adentrarnos en este análisis.

\section{Las relaciones entre hombres}

Analizar las masculinidades actuales implica poner sobre la mesa los mandatos que, como tales, funcionan como imperativos y que organizan esos modos de masculinidad. Es en ese arduo trabajo de los varones de demostrar-se hombres "de verdad" que reside una importante cuota de sufrimiento y malestar.

A partir del trabajo de Rita Segato, podemos pensar que el elemento central de las masculinidades tiene que ver con el ejercicio del poder, y la violencia es uno de sus instrumentos. Esto nos permite apartarnos de ciertos análisis esencialistas y empezar a poner el foco en los aspectos vinculares y relacionales para empezar a explicar la emergencia de situaciones de violencia.

Esta antropóloga enuncia una tesis que no debemos perder de vista:

Hay dos ejes en el ejercicio de la violencia: la acción en un eje vertical, de la relación agresor víctima, y en un eje horizontal, en donde la acción está dirigida a otros hombres de la fratria en donde se da cuenta de la propia potencia y capacidad de crueldad (Segato, 2018:45). 
En este sentido, resulta necesario hacer foco en las relaciones que se establecen entre los hombres en un espacio de encierro. Pero ello no solo atañe a quienes están privados de la libertad, sino también a aquellos otros que pueblan ese espacio desde su actividad laboral. ¿Cómo se vinculan los varones en esos espacios? ¿Qué aspectos relacionales se magnifican y cuales se ocultan?

No todo en la cárcel es violencia, y eso lo sabemos quiénes hemos transitado esos espacios. Por ende, resulta necesario alejarnos de esa mirada prejuiciosa que no permite rescatar y ni valorizar los vínculos que allí se generan, que son muchas veces los que sostienen y arman a los sujetos para enfrentar situaciones de desamparo y angustia. Esa grupalidad, que los detenidos llaman "ranchada" o a la que les empleades penitenciaries aluden como "camaradas" o "banda" son esos pequeños reductos de pertenencia, de confianza, pero que cuyo ingreso y permanencia no siempre es sencillo: aun cuando no exista esta grupalidad siempre hay un intento de pertenecer, al menos, al grupo de los hombres. Segato hace referencia a estos espacios como cofradías masculinas, como la fratría, aquel lugar de pertenencia al cual se ingresa pero que siempre debe probarse ser merecedor. En este punto, podemos ver una disposición a la competencia -con los antagonistas o con los mismos integrantes-, a la búsqueda de dominio, al desafío como una serie de actitudes y conductas que buscan asegurar el ingreso al exclusivo club de masculinidad.

Siguiendo con el análisis, Sofía Mosqueda (2018), retomando a Vicky Shultz, describe una serie de comportamientos degradantes como violencia sexista, anclados fundamentalmente en los estereotipos de género, en donde la violencia sexual puede ser una de las herramientas, pero no la única. Este comportamiento, por lo tanto, se traduce en que haya hombres en posiciones de poder que acosan tanto a mujeres como a hombres que son considerados menos hombres según los parámetros tradicionales para preservar su posición dominante y su sentido de la masculinidad. Se trata, pues, de un ejercicio de poder. Esta mención resulta importante para poder pensar que, aún dentro del grupo de los hombres, no todos tienen el mismo estatus.

Por ello, esa misma violencia y necesidad de separación que existe respecto de las mujeres también existe con otros hombres conside- 
rados menos hombres: los homosexuales, las identidades trans, los sensibles, los locos, los pibitos, los condenados por delitos sexuales, y muchos más. En este punto, lo que resulta esclarecedor es ubicar el mecanismo por el cual siempre hay una parte que se separa del todo, que busca diferenciarse para reafirmar la propia inclusión en el grupo de hombres considerados "de verdad". Y, como mencionaba $u t$ supra, esta forma de relación no es privativa de quienes se encuentran detenidos, sino que también los varones penitenciarios se encuentran subsumidos tras su lógica.

En este sentido, la primera diferencia que podemos encontrar es entre oficiales y suboficiales. El grupo que detenta el poder de tomar decisiones es muy reducido, y el resto queda en un estatus de inferioridad que es subrayado todo el tiempo. Pero en un sistema de jerarquías muy instalado, como sucede en los espacios militarizados, hasta la mínima diferencia es utilizada como signo de definición y exclusión. Es habitual escuchar la queja de celadores respecto de que "los presos tienen más poder que nosotros", porque la jerarquía no siempre responde a las formalidades, sino que claramente se encuentra atravesada por la posibilidad de ejercicio de cierto poder. No es gratuito quedar excluido de un grupo "de élite", ya que es ello lo que permite el despliegue de una serie de estrategias tanto para ser admitido como para no dejar de integrarlo.

En este punto, Segato describe la importancia de los otros hombres en los actos violencia. Tomando como ejemplo la violación, plantea que "aunque el violador actúe solo, otras presencias se hacen sentir junto a él" (2018:41): los llama "interlocutores en la sombra", esa compañía que le exige, que lo prueba, que lo insta, que lo lleva a exhibir su posición masculina ante otros. Además, va a decir que para los hombres el mandato funciona así:

Mostrar y demostrar que se tiene la piel gruesa, encallecida, desensitizada, que se ha sido capaz de abolir dentro de sí la vulnerabilidad que llamamos compasión y, por tanto, que es capaz de cometer actos crueles con muy baja sensibilidad a sus efectos. Todo esto forma parte de la historia de la masculinidad que es también la historia de vida del soldado (Segato, 2018:46). 
Es decir, siempre dar cuenta de la capacidad de potencia, demostrar que se hace, que se sabe, que se toman decisiones, que se puede doblegar al otro; en definitiva, que se es hombre de verdad.

\section{Las relaciones con las mujeres}

Pero no es sólo en la relación con los iguales en dónde se construye la identidad masculina, sino que también se conforma a partir de un rechazo y una diferencia de lo femenino. María Isabel Gil (2019) plantea que:

La masculinidad asociada al poder, el control, el valor, el dominio de la razón, la posesión del conocimiento, el gobierno de lo público y la independencia individual, configuraron la identidad del varón. Para poder llevar a cabo esas tareas debe delegar las otras funciones necesarias e imprescindibles para la supervivencia, por ser tediosas y cotidianas, a las mujeres, pero que sin su implementación, no podría existir un desarrollo de las otras (2019: párr. 13).

Esas otras tareas en general son llevadas a cabo por mujeres. La temática de estas relaciones es muy amplia. A riesgo de simplificar y recortar demasiado, referiré sólo algunas que aparecen con mayor pregnancia en la prisión.

Por un lado, son pocas las mujeres que habitan el espacio de una prisión de varones. En general, están reservadas a ellas las funciones administrativas y aquellas ligadas al cuidado: algunas enfermeras y médicas, docentes, talleristas e integrantes de los equipos técnicos como psicólogas, trabajadoras sociales y terapistas ocupacionales. Las mujeres no ocupan cargos de gobierno de la prisión, y si lo hacen es a riesgo de masculinizar su autoridad o bien quedan subordinadas a las órdenes de un hombre.

Por otro lado, las visitas de quienes están detenidos son fundamentalmente mujeres: madres, esposas, hijas, cuñadas y niñes. Los días en que se desarrollan las visitas podemos ver las inmediaciones de la cárcel atestadas de mujeres esperando el ingreso, con paquetes y niñes, aseguran la subsistencia cotidiana y sostenimiento el vínculo con les hijes. Tareas de cuidado, nuevamente. 
Así, al interior de la cárcel se reproduce el estereotipo de género que restringe a las mujeres al ámbito de lo doméstico, aunque lo doméstico sea fuera de casa y en un espacio laboral. Estas afirmaciones no pretenden ser una crítica a las tareas desarrolladas por mujeres, pero sí dar cuenta de cómo el estereotipo de mujeres cuidadoras es el que empuja a los varones a desentenderse de muchas de esas tareas y comportamientos, pues su ejercicio los “feminiza”. En este punto, podemos observar que dentro del pabellón existe una jerarquía que ordena roles y tareas: habrá quienes tengan a su cargo el liderazgo del pabellón y otros que se encarguen de cuestiones organizativas, pero siempre el último eslabón de la cadena de poder es ocupado por aquellos que realizan las tareas típicamente femeninas. Estos serán considerados "gatos", "lavataper" o se los llamará con un apodo femenino, pero siempre será desde una posición subordinada, despreciada y desvalorizada.

Por su parte, la sensibilidad es rechazada, y por tanto resulta algo de lo cual es necesario sustraerse. Los varones no transitan los momentos de angustia tan libremente como a veces es necesario. Vemos que en varias ocasiones se retiran a lamer sus heridas en soledad, en el confinamiento de su celda o incluso en sectores de aislamiento, en donde es posible sustraerse de la mirada de otros. Pero esa sensibilidad negada no es sólo respecto de los propios sentimientos. También es negada la empatía, la capacidad de conmoverse por la situación de otros $^{1}$. La indiferencia de muchos trabajadores penitenciarios respecto del sufrimiento de los detenidos se puede pensar como un mecanismo defensivo o como un mero acto de crueldad, pero aun así no deja de ser lo sensible algo que se excluye de la esfera de la masculinidad.

Hace unos pocos días, en el marco de mi trabajo como psicóloga en una cárcel, se me solicita la atención de un detenido que había quedado "afectado luego de una audiencia judicial", sin mayores precisiones que esas. A pesar de su reticencia inicial, el joven puede dar

1 En otro artículo (Marengo, 2019) he profundizado sobre esa naturalización del sufrimiento del otro que puede pensarse como una forma de crueldad del des-auxilio, en palabras de Silvia Bleichmar. Esa indiferencia ante el padecer, se hace presente en las pequeñas y banales acciones crueles, que no hacen más que sostener y perpetuar la perversidad de la institución penitenciaria. 
cuenta durante el encuentro de su enojo y frustración por una resolución que consideraba injusta, llegando a angustiarse por ello. A partir de eso, trabajamos sobre dichos sentimientos y le ofrecí la posibilidad de una nueva entrevista si la necesitaba. Frente a esto, me agradece, pero la rechaza, y se retira con claros signos de haber estado llorando. Cuando ingreso a mi oficina, de espaldas, escucho que se dirige a los celadores que lo llevaron diciendo con tono agresivo: "no sé para qué me llaman, si no sirven para nada”. Esta pequeña viñeta quizás nos permita situar varios puntos que veníamos desplegando. ¿Qué pasa cuando emerge la angustia delante de otros hombres? Llorar es un signo de debilidad, aun cuando esa angustia derive de las arbitrariedades que pueblan el encierro y que tanto daño producen. $Y$ es cuando aparece algo que lesiona el sentimiento de masculinidad que surge la otra defensa: el desprecio de la mujer y de todo lo asociado a lo femenino. Yo no sirvo para nada, el encuentro con los propios sentimientos tampoco. Pero esto no sucede delante de mí en el espacio privado del consultorio, sino que justamente es mostrado a otros hombres. En este caso, el acto violento contra la mujer es la contraseña que asegura el ingreso y permanencia entre los hombres de verdad.

Las mujeres que habitamos esos espacios también nos vemos atravesadas por estos ejercicios de masculinidad. No vamos a hablar aquí de formas extremas de violencia sexual, pero sí de hechos cotidianos que se transforman en conductas sexistas de discriminación y degradación, que muchas veces por pequeñas y cotidianas se vuelven invisibles.

También, existen esas otras violencias que al ser ejercidas desde lugares de autoridad ejercen un efecto de legitimación de aquellas que ocurren en los espacios que no lo son. Los paternalismos, las ridiculizaciones, la exclusión, la marginación, el bloqueo de información y el sabotaje del trabajo, los gritos o faltas de respeto, las asignación de tareas que no tienen que ver con su puesto, el ignorar, interrumpir y moderar el comportamiento de las mujeres, son formas de acoso. "Estas formas no sexuales de sexismo y abuso son mucho más prevalentes que los avances sexuales y la coerción sexual, y además causan daños tanto profesionales como personales muy similares a los del acoso sexual” (Mosqueda, 2018: párr. 7). Todo aquello que amenace un lugar 
de jerarquía será combatido y la cultura del disciplinamiento se pondrá en marcha. Entonces, no hay un lugar para la sensibilidad, para las preguntas, para los errores... Vigilancia, control y poder siguen más vigentes que nunca.

\section{"Las herramientas del amo nunca desmontarán la casa del amo", Audre Lorde (1979)}

Este recorte de cotidianidades de la prisión no pretende ser abarcativo de lo que allí sucede, pues existen muchas otras formas de vinculación que escapan al análisis actual pero que también requieren ser consideradas. Aun así, podemos observar que la cárcel tiene un rol fundamental como reproductora de ciertas violencias que no son privativas de ese espacio, pero que sí encuentran las condiciones para magnificarse.

Muy lúcidamente, Silvia Bleichmar (2019) le da preponderancia al concepto de producción de subjetividades, entendiendo que ciertos aspectos de las relaciones sociales pautan, mediatizan, vehiculizan $\mathrm{y}$ constituyen modos de intercambios sociales que justamente tienen lugar en un contexto histórico social que los hace posible. No hay sujeto que no se constituya a partir de las condiciones contextuales que pautan determinadas formas de subjetivación. Esta psicoanalista va a decir que la producción de subjetividad...

Regula los destinos del deseo en virtud de articular, del lado del yo, los enunciados que posibilitan aquello que la sociedad considera "sintónico" consigo misma. Las formas de la moral, las modalidades discursivas con las cuales se organiza la realidad, que no solo es articulada por el código de la lengua sino por las coagulaciones de sentido que cada sociedad instituye (Bleichmar, 2019:96).

La cárcel toma a su mando la administración del castigo respecto de quienes han sido señalados como infractores del pacto social a partir de la ficción del ideal resocializador. Pero, en su interior, la maquinaria patriarcal funciona sin demasiadas fisuras. La vigilancia, el control de los cuerpos, la deshumanización de los vínculos, la autoridad incuestionable, el castigo abusivo y arbitrario, nos remiten más a 
un funcionamiento patriarcal que a un trabajo resocializador. Incluso, para otorgar libertades anticipadas lo que entra en evaluación es la capacidad de cumplir con ciertos mandatos de género: haber accedido a un trabajo, tener un proyecto familiar, hacerse cargo del cuidado de los hijos. ¿Es este el espacio adecuado para poder combatir la violencia machista y poner en cuestión los estereotipos de género?

Las prisiones no existen desde hace tanto tiempo. Foucault describe su origen en el siglo XIX. Sin embargo, hoy no podemos pensar en otras formas de dirimir los conflictos sociales más que por la vía del encierro punitivo. Aun cuando percibimos que la respuesta no es eficaz, es el único horizonte que aparece como posible.

Por este motivo, necesitamos poner en discusión las estructuras patriarcales que sostienen a la prisión. No sólo la administración de la justicia es patriarcal, la ejecución de las penas produce y reproduce de formas mucho más crueles la cultura machista, transformándose en un círculo vicioso del que resulta muy difícil poder sustraerse. La cárcel se transforma en esa habitación vieja del fondo de la casa, en donde dejamos todo aquello que no nos sirve y cerramos la puerta. El desorden queda oculto hasta que tenemos que sacar algún trasto y vemos que está en iguales o peores condiciones que cuando lo tiramos ahí.

La violencia como esa forma desnuda de ejercicio de poder atraviesa la constitución de las subjetividades neoliberales, y en tanto problemática social debe poder ser abordada en su conjunto. En los últimos años, asistimos a un avance gigantesco en el reconocimiento de las desigualdades de género y las formas de regular y sancionar conductas que lesionan los derechos de las mujeres y otras identidades en disidencia, pero aún quedan espacios en donde las formas de violencia no se han puesto lo suficientemente en cuestión.

¿Es posible que en el espacio carcelario se favorezca la implicación subjetiva y la responsabilización individual si existe toda una cultura del ensañamiento con quienes fueron victimarios? ¿Qué posibilidades hay de construcción de vínculos de empatía, de semejanza, de reparación en un espacio tan hostil?

Considero que plantear esta discusión no es promover la impunidad de los actos de violencia, pero sí ubicar que necesitamos un debate 
social respecto de aquello que sucede en las cárceles. Si la problemática es social, la salida también deberá serlo.

Ileana Arduino (2017) plantea que "las respuestas a la altura de la lucha y los costos en vidas de mujeres serán aquellas que erradiquen las condiciones de producción y reproducción de esta normalidad violenta que expresa un régimen de estatus basado en el género" (2017: párr. 37). Continúa diciendo que "para ello habrá que producir intersección cabal entre perspectivas de género y garantismo, no por capricho epistemológico ni snobismo conceptual, sino una exigencia básica de reconocimiento y no discriminación” (2017: párr. 37).

Además, resulta importante mencionar que, desde una perspectiva de la criminología atravesada por los estudios de género, se viene abogando por una modalidad de justicia que sea restaurativa y no meramente punitivista, en donde se privilegien otras formas de cumplimiento de las penas. Pero en el caso de que las penas sí sean de prisión se hace necesario pensar cómo se transitan esos espacios y qué políticas públicas existen para ello.

Si como plantea Silvia Bleichmar (2019) el horizonte es reconstruir el pacto intersubjetivo, serán necesarias todas aquellas operaciones que desde la ética del reconocimiento del semejante habiliten a la creación de lazos de empatía, de reconocimiento, de humanización, de sensibilización. Tal como lo plantea la autora, es en las contradicciones del sistema social -patriarcal, podríamos agregar-, en sus huecos, en sus filtraciones, en donde anida la posibilidad de nuevas subjetividades. "Pero éstas no pueden establecerse sino sobre nuevos modelos discursivos, sobre nuevas formas de redefinir la relación del sujeto singular con la sociedad en la cual se inserta y a la cual quiere de un modo u otro modificar" (Bleichmar, 2019:96).

\section{Referencias bibliográficas}

Arduino, Ileana (2017). Ni machos ni fachos. Revista Anfibia. Recuperado de: http://revistaanfibia.com/ensayo/ni-machos-ni-fachos/

Bleichmar, Silvia (2006). Violencia social-violencia escolar. De la puesta de límites a la construcción de legalidades. Buenos Aires, Argentina, Editorial Noveduc.

Bleichmar, Silvia (2011). La construcción del sujeto ético. Buenos Aires, Argentina, Editorial Paidós. 
Bleichmar, Silvia (2019). La subjetividad en riesgo. Buenos Aires, Argentina, Editorial Topía.

Fernández Boccardo, Marta (2018). Masculinidades y mandatos del patriarcado neoliberal. Una lectura psicoanalítica con perspectiva de género. Buenos Aires, Argentina, Entre Ideas.

Foucault, Michel (1976). Vigilar y castigar. Bogotá, Colombia, Siglo Veintiuno.

Gil, Maribel (26 de diciembre de 2019) El origen del sistema patriarcal y la construcción de las relaciones de género. Ágora. Recuperado de: https://www.agorarsc. org/el-origen-del-sistema-patriarcal-y-la-construccion-de-las-relaciones-de-genero/\# ftn29

Marengo, Malvina (2019). "De nadies y de otros. Recortes de una práctica en contextos hostiles". En W. Donato (Ed.) Experiencias de escribir la experiencia Vol. II (171-193). Rosario, Argentina, Editorial Glosa.

Mosqueda, Sofía (6 de septiembre de 2018). Cuando el acoso no es sexual (pero sí es sexista). Nexos. Economía y sociedad. Recuperado de https://economia.nexos. com.mx/?p=1836\#.XxDytI5jfNA.email

Peretti, María Laura (2018). “Voces masculinas tras las rejas”. En M. Fernández Boccardo (Ed.) Masculinidades y mandatos del patriarcado neoliberal. Una lectura psicoanalítica con perspectiva de género (103-123). Buenos Aires, Argentina, Entre Ideas.

Segato, Rita (2010). Las estructuras elementales de la violencia. Ensayos sobre género entre la antropología, el psicoanálisis y los derechos humanos. Ciudad de Buenos Aires, Argentina, Prometeo Libros.

Segato, Rita (2018). Contrapedagogías de la crueldad. Ciudad de Buenos Aires, Argentina, Prometeo Libros.

Sozzo, Máximo (2008). Populismo punitivo, proyecto normalizador y "prisión-depósito" en Argentina. Jura Gentium Rivista di filosofia del diritto internazionale e della politica globale. Recuperado de: https://www.juragentium.org/topics/latina/ es/sozzo.htm\#*

Wacquant, Löic (2004). Las cárceles de la miseria. Buenos Aires, Argentina, Manantial.

Ley $\mathrm{N}^{\circ} 24660$ - Ley de Ejecución de la pena privativa de la libertad (1996). Buenos Aires, Argentina, Congreso de la Nación.

Recibido: 8/02/2021

Aceptado: 27/09/2021 